Original article

\title{
Risk factor analysis and method development for predicting the recurrence of gastroduodenal ulcer bleeding
}

\author{
Sergey N. Potakhin, Yuri G. Shapkin \\ Saratov State Medical University, Saratov, Russia
}

Received 12 August 2020, Revised 2 November 2020, Accepted 18 November 2020

(C) 2020, Potakhin S.N., Shapkin Y.G

(C) 2020, Russian Open Medical Journal

\begin{abstract}
Objective - To clarify clinical, laboratory and endoscopic signs of a high recurrence risk of gastroduodenal ulcer bleeding (GDUB) and to develop a multifactorial method for its prediction.

Material and Methods - The research was completed over 2019-2020. The study took place in two stages. At the first stage, 409 patients with GDUB, who were treated at the emergency surgical department of Saratov City Clinical Hospital No. 6 from 1991 to 2000 , were included in the study. During that time, endoscopic hemostasis therapy was used in a few cases, while modern antisecretory therapy has not yet been developed and carried out. Two groups of patients were compared: with recurrent bleeding (104 patients) and without recurrent bleeding (305 patients). At the second stage, a retrospective analysis of the outcomes of treating 126 patients with GDUB, cared for at the clinic from 2001 to 2009, was carried out. During this period of time, assistance for this pathology was the most complete and matched all current standards. The analysis included 63 patients with recurrent bleeding and 63 patients without recurrent bleeding. We conducted a comparative analysis of the developed method for predicting bleeding recurrence versus the classifications by J.A. Forrest (1974) and G.P. Giderim (1992) in our original modification.

Results - At the first stage of the study, the most significant signs for predicting recurrent bleeding were identified as unstable hemodynamics, severity of blood loss, nature of vomiting, presence of concomitant pathology, state of the ulcer surface sensu J.A. Forrest; and localization, size and depth of the ulcer. We determined their informative value in assessing the risk of recurrent bleeding and developed a novel method of its prediction. Taken alone, each of nine predictive signs has a correlation, comparable in the magnitude with patient allocation into each group (based on the absolute value of gamma, ranging $0.49-0.66$ ); the prediction accuracy is $60-74 \%$, with a positive predictive value of $35-49 \%$. The measure of the gamma relationship for splitting patients among groups by the original method based on nine features in conjunction with each other was $-0.79(p<0.001)$.

Conclusion - Prediction of recurrent bleeding by one or two signs is inferior in informational content (although insignificantly) to the multifactorial method. The developed method for predicting the recurrence of ulcer bleeding from nine signs has an optimal ratio of sensitivity and specificity, which ensures a prediction accuracy of over $70 \%$ and a positive predictive value of $68.9 \%$.
\end{abstract}

Keywords: gastroduodenal ulcer bleeding, prediction of recurrent bleeding, risk assessment, comparative analysis of methods, signs of high-risk recurrence.

Cite as Potakhin SN, Shapkin YG. Risk factor analysis and method development for predicting the recurrence of gastroduodenal ulcer bleeding. Russian Open Medical Journal 2020; 9: e0419.

Correspondence to Sergey N. Potakhin. E-mail: potakhin sn@rambler.ru.

\section{Introduction}

Risk assessment and projection of disease course in conditions of gastroduodenal ulcer bleeding is of priority importance for choosing the treatment tactics. This is emphasized both in the recommendations of International Consensus Group for treating the patients with non-varicose bleeding from the upper gastrointestinal tract (GIT) in 2010 and 2019, as well as in the national recommendations developed at the Plenum of the Russian Society of Surgeons Board in June 2014 [1-3].

The O. Blatchford scale recommended for use, for example, uses a differentiated approach to hospitalization of patients with gastroduodenal bleeding, also called gastroduodenal hemorrhage (GDH). However, some studies claim that indications for hospitalization or early endoscopy, as well as for intensive care may be based solely on the assessment of pulse and systolic blood pressure, along with the results of gastric lavage $[4,5]$. According to other authors, the experience and intuition of a clinician is of great importance in risk stratification $[6,7]$.

Apparently, it is the experience and deep understanding of disease course characteristics that allow us considering the risks as separate conditions. Whether the bleeding continues or not, whether there is a risk of its recurrence, whether blood transfusion is indicated, and what is the probability of death cannot be determined on a single scale. All these conditions have their own characteristic clinical, laboratory and endoscopic manifestations. The ability to identify these manifestations is no less significant than use of rating scales. 
Objective. To clarify clinical, laboratory and endoscopic signs of a high recurrence risk of gastroduodenal ulcer bleeding (GDUB) and to develop a multifactorial method for its prediction.

\section{Material and Methods \\ Study design}

Our research was conducted in 2019-2020. A comparative analysis of the clinical, laboratory and endoscopic characteristics of patients with and without recurrence of bleeding and a retrospective analysis of the prediction results of bleeding recurrence in patients with GDUB was carried out. The study took place in two stages.

At the first stage, the study included 409 patients with GDUB, treated at the emergency surgical department of the Academician V.N. Koshelev Saratov City Clinical Hospital No. 6 from 1991 through 2000. The study excluded patients operated upon admission, based on emergence indications, for ongoing bleeding or a high risk of its recurrence. During this period of time, endoscopic hemostasis was used in isolated cases, while modern antisecretory therapy has not yet been developed. Two groups of patients were compared. The first group included patients who had recurrent bleeding (104 patients), the second group encompassed patients without recurrent bleeding (305 patients). Clinical data on patients were obtained from an electronic database constructed with the FoxPro 2.0 program (Fox Software, USA, 1991), developed in 1991 and used at the clinic until 2009.

At the first stage of the study, the following tasks were set: to assess the significance of individual signs for predicting the recurrence of GDUB and to develop on their basis a method for predicting the recurrence of hemorrhage.

At the second stage of our study, the informativeness of the developed method was assessed on an independent sample in comparison with J.A. Forrest and G.P. Giderim classifications $[8,9]$. The study included 126 patients with GDUB. The patients were treated at the same hospital from 2001 to 2009. During this period of time, GDUB treatment was the most complete and met all current standards. In 63 patients of this group, recurrence of bleeding was identified, whereas remaining 63 subjects did not have it. The analysis did not involve patients operated upon admission at the peak of bleeding or with the threat of recurrent bleeding. Clinical data on patients were obtained from an electronic database constructed with FoxPro 2.0 software.

\section{Clinical data treatment techniques}

When processing the clinical data on patients, we used Excel and Statistica 6.0 software (StatSoft, USA). The patient data in the second group were uploaded to the Integrated Medical Information and Analytical System, developed at the department in 2017, hereinafter referred to as the System (S.N. Potakhin and N.V. Kuzmichev). Certificate of state registration of the computer program No. 2020615085, dated 14 May, 2020, was issued to S.N. Potakhin and N.V. Kuzmichev. The certificate of state registration of the database is dated 14 May, 2020 and has No. 2020620768. The System details can be found at http://medical.elibs.ru. We conducted a comparative analysis of the developed method for predicting GDUB recurrence with classifications by J.A. Forrest [8] and G.P. Giderim [9] in our modification. The results of a comparative analysis of other methods were published previously [10].

\section{Statistical analysis}

Statistical analysis of the data was carried out, using the Statistica 6.0 software package (StatSoft, USA). In the statistical data analysis, only patients with a full set of signs were taken into account; in the absence of individual values, they were excluded from the analysis.

Descriptive statistics were used to compute mean, variance, and standard deviation for quantitative data, while probability was computed for dichotomous variables. The significance of the differences for each trait between the groups of patients with and without recurrent bleeding was assessed by Student's t-test. At a significance level of $p<0.05$, the difference was considered significant. Of nonparametric methods, the Mann-Whitney $U$ test, the Kolmogorov-Smirnov two-factor test, and the Wald-Wolfowitz runs test were used. Using the Goodman and Kruskal's gamma, which is a measure of rank correlation, i.e., the similarity of the orderings of nonparametric data, we analyzed the significance for risk assessment of individual signs, used in different methods of predicting bleeding recurrence. This indicator characterized, whether it is possible to determine the patient allocation to the group with or without recurrent bleeding by the value of the predictive feature.

The informativeness of prediction methods was assessed in terms of their sensitivity (Se) and specificity (Sp). Sensitivity was understood as the ratio of the number of cases, correctly predicted by the recurrent bleeding method, to the total number of recurrent bleeding cases. Accordingly, the specificity is the ratio of the confirmed case number of low-risk recurrent bleeding to the total number of patients without recurrent bleeding. The method accuracy (Ac) is the ratio of all cases of correct risk verification to the total number of examined patients. We also calculated the positive predictive value - i.e., predictive value of a positive outcome (PPV; hereinafter referred to as the predictive value). This indicator represented the proportion (probability) of a hemorrhage recurrence among all patients at high risk. These four described indicators are represented by percentages.

When developing a new multifactorial method for predicting recurrence of GDUB, a logical-algebraic approach was used. Based on the results of a comparative analysis, the most significant predictive features were selected. Then, a weighting coefficient value was selected empirically for each feature. At this particular value of a predictive feature, the patients were best allocated to a certain group. We used one, two or more features, or signs, gradually increasing their number. For each combination, the information content of the forecast (sensitivity, specificity, accuracy and predictive value) was assessed. The option, characterized by the optimal ratio of information content, formed the basis of the algorithm for predicting GDUB recurrence.

\section{Results}

Results of a comparative analysis of patients with and without recurrent bleeding

We analyzed the data of 409 patients treated at the State Healthcare Institution Academician V.N. Koshelev Saratov City Clinical Hospital No. 6 in the period from 1991 through 2000. The patients were divided into two groups. Group 1 consisted of 104 patients (25.4\%) who had a relapse of GDUB, whereas group 2 contained 305 patients $(74.6 \%)$ without recurrent bleeding. The main clinical, laboratory, and endoscopic traits of patients are presented in Table 1. 
Table 1. Basic clinical, laboratory and endoscopic characteristics of patients

\begin{tabular}{|c|c|c|c|}
\hline Characteristics & Group $1 \mathrm{~N}=104$ & Group $2 \mathrm{~N}=305$ & p-level \\
\hline Age, years, $\mathrm{M} \pm \mathrm{SD}$ & $51 \pm 14.8$ & $48 \pm 15.2$ & 0.043 \\
\hline men, $\%(n / N)$ & $71(74 / 104)$ & $74(227 / 305)$ & 0.514 \\
\hline Concomitant pathology, \% (n/N) & $67.4(70 / 104)$ & $42.6(130 / 305)$ & $<0.001$ \\
\hline Severe or complicated course of concomitant ailments, $\%(n / N)$ & $22(23 / 104)$ & $9.2(28 / 305)$ & $<0.001$ \\
\hline Combination of concomitant ailments, $\%(n / N)$ & $26(27 / 104)$ & $13.4(41 / 305)$ & $<0.001$ \\
\hline Ulcer in anamnesis, \% (n/N) & $57(59 / 104)$ & $53(163 / 305)$ & 0.608 \\
\hline History of ulcer complications, \% (n/N) & $24(25 / 104)$ & $16.4(50 / 305)$ & 0.562 \\
\hline Surgery for ulcer complications in anamnesis, $\%(n / N)$ & $17(18 / 104)$ & $11(34 / 305)$ & 0.104 \\
\hline Duration of bleeding, days, $M \pm S D$ & $3.6 \pm 4.44$ & $3.6 \pm 4.29$ & 0.988 \\
\hline Complaints of weakness, $\%(n / N)$ & $89(93 / 104)$ & $79(242 / 305)$ & 0.024 \\
\hline Collapse prior to hospitalization, \% (n/N) & $32(33 / 104)$ & $12(38 / 305)$ & $<0.001$ \\
\hline Vomiting blood, \% (n/N) & $67(70 / 104)$ & $48(146 / 305)$ & $<0.001$ \\
\hline Stool with black feces, \% (n/N) & $79(82 / 104)$ & $84(255 / 305)$ & 0.372 \\
\hline Unstable hemodynamics, \% (n/N) & $55(57 / 103)$ & $25(72 / 288)$ & $<0.001$ \\
\hline Pulse at admission, beats per min, $M \pm S D$ & $94 \pm 13.3$ & $87.8 \pm 12.41$ & $<0.001$ \\
\hline Systolic blood pressure, mmHg, $\mathrm{M} \pm \mathrm{SD}$ & $121.7 \pm 25.69$ & $124.5 \pm 21.48$ & 0.157 \\
\hline Pulse $\geq 100$ per $\min , \%(n / N)$ & $34(35 / 103)$ & $16(47 / 288)$ & $<0.001$ \\
\hline Systolic blood pressure $<100 \mathrm{mmHg}, \%(\mathrm{n} / \mathrm{N})$ & $11(11 / 103)$ & $3.5(10 / 288)$ & $<0.001$ \\
\hline CBV deficit, $\mathrm{ml}, \mathrm{M} \pm \mathrm{SD}$ & $895.8 \pm 285.67$ & $723.4 \pm 338.28$ & $<0.001$ \\
\hline Mild blood loss, \% ( $/ \mathrm{N})$ & $13(13 / 104)$ & $34(104 / 304)$ & $<0.001$ \\
\hline Moderate blood loss, \% (n / N) & $54(56 / 104)$ & $44(134 / 304)$ & 0.040 \\
\hline Severe blood loss, $\%(n / N)$ & $33(35 / 104)$ & $22(66 / 304)$ & $<0.001$ \\
\hline Gastric ulcer, \% (n/N) & $37(38 / 104)$ & $26(78 / 305)$ & 0.032 \\
\hline Ulcer in posterior wall of duodenum, \% (n/N) & $67(28 / 42)$ & $26(44 / 169)$ & $<0.001$ \\
\hline Size of gastric ulcers, $\mathrm{cm}, \mathrm{M} \pm \mathrm{SD}$ & $2.4 \pm 1.54$ & $1.2 \pm 0.62$ & $<0.001$ \\
\hline Size of duodenal ulcers, $\mathrm{cm}, \mathrm{M} \pm \mathrm{SD}$ & $1.2 \pm 0.98$ & $0.8 \pm 0.52$ & $<0.001$ \\
\hline Ulcer depth $\geq 4 \mathrm{~mm}, \%(\mathrm{n} / \mathrm{N})$ & $44(46 / 104)$ & $16(48 / 305)$ & $<0.001$ \\
\hline Forrest la and Forrest Ib, \% (n/N) & $6(6 / 104)$ & $5(14 / 305)$ & 0.632 \\
\hline Forrest Ila, \% (n/N) & $42(44 / 104)$ & $30(90 / 305)$ & 0.001 \\
\hline Forrest IIb, \% (n/N) & $20(21 / 104)$ & $9(26 / 305)$ & 0.016 \\
\hline Forrest IIc, \% (n/N) & $5(5 / 104)$ & $5(16 / 305)$ & 0.862 \\
\hline Forrest III, \% (n/N) & $27(28 / 104)$ & $53(159 / 305)$ & $<0.001$ \\
\hline
\end{tabular}

$\mathrm{CBV}$, circulating blood volume. $\mathrm{M} \pm \mathrm{SD}$ is mean with standard deviation. $(\mathrm{n} / \mathrm{N})$ is the number of patients with the presence of parameter and total number of patients with data on this parameter.

Table 2. Gamma-values for significant signs of high risk of recurrent gastroduodenal ulcer bleeding

Signs of high-risk gastroduodenal ulcer bleeding recurrence

Ulcer in anterior wall of duodenum

Ulcer depth $\geq 4 \mathrm{~mm}$

Unstable hemodynamics

Size of duodenal ulcer

Systolic blood pressure $<100 \mathrm{mmHg}$

Collapse prior to hospitalization

Concomitant pathology

Ulcer size independent of its localization

Severity degree of concomitant pathology

Pulse $\geq 100$ per min

Distribution sensu J.A. Forrest classification

Number of comorbidities

Vomiting blood

Gastric ulcer size

Combination of concomitant ailments

The degree of blood loss sensu A.I. Gorbashko

Ulcer in posterior wall of duodenum

Complaints about weakness

History of gastric resection or vagotomy

Circulating blood volume deficit

Duodenal ulcer

Pulse

Gastric ulcer

Surgery for ulcer complications in anamnesis

Red blood cell coun

Blood hemoglobin level

Age
Gamma values p-level

$0.629<0.001$

$-0.619<0.001$

$-0.574<0.001$

$-0.560<0.001$

$-0.537<0.001$

$-0.530<0.001$

$-0.470<0.001$

$-0.467<0.001$

$-0.462<0.001$

$-0.450<0.001$

$0.432<0.001$

$-0.422<0.001$

$-0.406<0.001$

$-0.390<0.001$

$-0.386<0.001$

$-0.384<0.001$

$-0.370<0.001$

$-0.368<0.001$

$-0.361 \quad 0.023$

$-0.321<0.001$

$0.295<0.001$

$-0.280<0.001$

$-0.253 \quad 0.001$

$-0.250 \quad 0.015$

$0.212<0.001$

$0.176 \quad 0.001$

$-0.129 \quad 0.017$
There were no differences in gender between the compared groups. In the group of patients with recurrent bleeding, the average age was significantly higher, and concomitant pathology was more common. At the same time, there were significant differences in the severity of concomitant pathology and in the number of diseases. Any clinically significant pathology, present in patients, was referred to as a comorbidity.

Patients of groups 1 and 2 equally habitually had an ulcer history. The difference in this feature, as well as in the incidence of ulcer complications (perforation and bleeding) in anamneses, were insignificant.

The groups did not differ from each other in the duration of bleeding (from its onset until hospitalization). At the same time, complaints of weakness, collapse before hospitalization and vomiting of blood were reliably more frequently detected in patients of group 1 . There were no differences between the groups in the frequency of occurrence of black stools.

In group 1, on admission, the pulse was significantly higher, and in one-third of patients it exceeded 100 beats per minute. There was no significant difference in the mean systolic blood pressure between the groups, but in group 1, a larger number of patients had systolic blood pressure below $100 \mathrm{mmHg}$. With a pulse rate of $\geq 100$ per minute - or smaller, but in the presence of a collapse before hospitalization, hemodynamics was considered unstable. There were twice as many such patients in group 1. 
Patients with recurrent bleeding initially had more circulating blood volume (CBV) deficit. Moreover, in one-third of cases, the CBV deficit exceeded $1000 \mathrm{ml}$, which corresponded to severe blood loss sensu the classification by A.I. Gorbashko [11].

The proportion of patients with gastric ulcers was higher in the first group. There were no significant differences in ulcer location in the stomach. However, for duodenal ulcers, there were differences in localization. In patients of group 1, ulcers were significantly more often localized on the posterior wall of the duodenum.

In the first group, stomach and duodenal ulcers were larger than in the second group. Deep ulcers (depth $\geq 4 \mathrm{~mm}$ ) were also found significantly more often in patients of the first group.

During the first endoscopic examination, over $60 \%$ of patients in group 1 had a thrombosed vessel or a blood clot in the ulcer (Forrest Ila, IIc). In group 2, there were fewer such patients, but ulcers under fibrin (Forrest III) were twice as common. Continuous bleeding (Forrest la, Ic) was equally common in both groups. Endoscopic hemostasis therapy was successfully performed in such patients.

The significance of the features, by which the groups differed from each other, was confirmed using nonparametric analytical methods, in particular, the measure of rank correlation Goodman and Kruskal's gamma. In total, we analyzed 88 features, reflecting various clinical, laboratory and endoscopic traits. Table 2 presents only significant predictive signs.

It should be noted that ordering predictive features by their absolute gamma values in Table 2 is rather arbitrary, because the gamma value may be influenced by the number of patients in subgroups when several characteristics are combined in one predictive sign - for example, size and location. E.g., the value of the measure of rank correlation was greater for the size of duodenal ulcers than for the size of gastric ulcers, since the number of patients with duodenal ulcers was greater. Still, this does not mean that, for gastric ulcers, size is less important in assessing the risk of recurrent hemorrhage. The same can be said about the localization of ulcers in the stomach and duodenum. Therefore, it is more correct to talk about ordering for the signs, unambiguously reflecting one characteristic of a patient, or for different versions of the presentation of one sign.

Table 3. Gamma relationship measurements for the simplest methods of assessing the risk of gastroduodenal ulcer bleeding recurrence

\begin{tabular}{lcc}
\hline Method for assessing the risk of recurrent hemorrhage & $\begin{array}{c}\text { Gamma } \\
\text { values }\end{array}$ & $p$ \\
\hline By size and location of the ulcer & -0.655 & $<0.001$ \\
By the ulcer depth & -0.619 & $<0.001$ \\
By the nature of hemodynamics & -0.574 & $<0.001$ \\
Sensu classification of G.P. Giderim & -0.542 & $<0.001$ \\
Sensu classification of J.A. Forrest & 0.487 & $<0.001$ \\
\hline
\end{tabular}

Table 4. Informative value of the simplest predictive methods and individual features in assessing the risk of gastroduodenal ulcer bleeding recurrence in the first group $(n=409)$

\begin{tabular}{lcccc}
\hline $\begin{array}{l}\text { Method for assessing the risk of } \\
\text { recurrent hemorrhage }\end{array}$ & \multicolumn{3}{c}{$\begin{array}{c}\text { Indicators of informative value of } \\
\text { diagnostic methods, \% }\end{array}$} \\
\hline By size and location of the ulcer & Se & Sp & Ac & PPV \\
By the ulcer depth & 44 & 73 & 71 & 44 \\
By the nature of hemodynamics & 55 & 75 & 70 & 44 \\
Sensu classification of G.P. Giderim & 56 & 82 & 68 & 42 \\
Sensu classification of J.A. Forrest & 68 & 57 & 60 & 35 \\
\hline
\end{tabular}

Se, sensitivity; Sp, specificity; Ac, accuracy; PPV, positive predictive value (i.e., predictive value of a positive outcome).

\section{Predicting recurrent bleeding from minimum number of features}

J.A. Forrest classification is the simplest method for assessing the risk of recurrent bleeding: it relies on just one sign - the condition of the ulcerated surface. There is a high risk of rebleeding with Forrest la, Ib, Ila and Ilb. However, according to the value of the gamma relationship measure, we can speak of several more signs that are no less significant in predicting the course of the ailment. Of endoscopic signs, these are the ulcer depth, size, and localization. Of clinical signs, this is unstable hemodynamics. Hypothetically, each of these features can be used as an independent simplest risk assessment methodology, along with the classification by J.A. Forrest. For example, taking into account ulcer size and location, the risk of recurrent bleeding should be considered high if the diameter of gastric and duodenal ulcers is $\geq 1.6 \mathrm{~cm} \geq 1 \mathrm{~cm}$, respectively. With an ulcer depth of $4 \mathrm{~mm}$ or more, or with unstable hemodynamics upon hospital admission, we can also speak of a high risk of recurrent bleeding. The classification by G.P. Giderim may be attributed to simple methods for predicting recurrent bleeding. We used it in our original modification, taking into account the nature of the ulcer bottom, as in the classification of J.A. Forrest, and the state of hemodynamics [10]. The values of the gamma relationship measure for simple risk assessment techniques are presented in Table 3.

Comparative analysis of the informative value of the simplest risk assessment techniques are presented in Table 4.

The indicators of the informative value of presented risk assessment methods did not differ much from each other, which implied an equivalence of the used features.

\section{Developing multifactorial method for predicting recurrent} bleeding

To improve the accuracy of predicting recurrent bleeding, we decided to develop a novel method, using a combination of the most significant features. Based on logical and algebraic principles and expert judgment, we managed to select nine features.

The signs for the developed method of predicting GDUB recurrence, criteria for assessing high risk, and weighting factors are presented in Table 5.

The algorithm for using the method is as follows. Symptoms of bleeding are assessed (pulse, systolic blood pressure at the time of hospitalization, the presence of bloody vomiting and collapse prior to hospitalization). The presence of any concomitant pathology is taken into account. The volume of blood loss is calculated by any available method (by corpuscular volume, blood specific gravity, hemoglobin level, or hematocrit). Next, an endoscopic examination is performed, in which the condition of the ulcer is assessed, according to the classification of J.A. Forrest, its localization, maximum size and depth. According to the Russian tradition and current national clinical guidelines, esophagogastroduodenoscopy is performed to all patients with clinical signs of GDUB within two hours. If the values of the signs meet the criteria for assessing high risk of GDUB recurrence, their weight coefficients are summed up.

The proposed risk assessment method requires taking into account all of the listed characteristics. Recurrent bleeding is predicted at a score of five or more. 


\begin{tabular}{|c|c|c|}
\hline $\begin{array}{l}\text { Signs for assessing the recurrence risk of } \\
\text { gastroduodenal ulcer bleeding }\end{array}$ & High risk assessment criteria & $\begin{array}{l}\text { Weighting } \\
\text { coefficient }\end{array}$ \\
\hline Unstable hemodynamics & Pulse $\geq 100$ per min. on admission and / or having a collapse before admission & 2 \\
\hline Hemorrhagic shock on admission to the hospital & Systolic blood pressure $<100 \mathrm{mmHg}$ at hospitalization & 2 \\
\hline The severity of blood loss & The presence of severe blood loss according to A.I. Gorbashko (over $1000 \mathrm{ml}$ ) & 2 \\
\hline Presence of vomiting blood & Vomiting of unchanged or reduced blood & 1 \\
\hline Presence of concomitant pathology & Presence of any clinically significant pathology & 1 \\
\hline Ulcer characterization sensu J.A. Forrest & $\begin{array}{l}\text { Forrest la, Forrest Ib, } \\
\text { Forrest Ila, Forrest Ilb }\end{array}$ & 1 \\
\hline Ulcer localization & $\begin{array}{l}\text { The body and cardiac section of the stomach; ulcers in posterior wall of duodenum; } \\
\text { multiple duodenal ulcers; and ulcers occupying more than one wall of the duodenum }\end{array}$ & 1 \\
\hline Ulcer size vs. its localization & 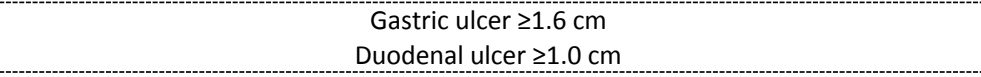 & 1 \\
\hline Ulcer depth & The presence of an ulcer $4 \mathrm{~mm}$ deep or more & 1 \\
\hline
\end{tabular}

Table 6. Informative value of methods for predicting gastroduodenal ulcer bleeding recurrence in an independent sample $(\mathrm{N}=126)$

\begin{tabular}{lcccc}
\hline $\begin{array}{l}\text { Method for assessing the risk of } \\
\text { recurrent hemorrhage }\end{array}$ & \multicolumn{4}{c}{$\begin{array}{l}\text { Indicators of informative value of } \\
\text { diagnostic methods, \% }\end{array}$} \\
\cline { 2 - 6 } & Se & Sp & Ac & PPV \\
\hline Sensu classification of J.A. Forrest & 90.5 & 20.6 & 55.6 & 53.3 \\
Sensu classification of G.P. Giderim & 82.5 & 73 & 78 & 75.4 \\
Based on nine features & 72.4 & 68.9 & 70.6 & 68.9 \\
\hline
\end{tabular}

Se, sensitivity; Sp, specificity; Ac, accuracy; PPV, positive predictive value (i.e., predictive value of a positive outcome).

The training sample included 353 observations with a full set of clinical, laboratory, and endoscopic data. Of these, there was a relapse of bleeding in 90 cases, and there was no recurrent bleeding in 263 cases. When using this method, a high risk of hemorrhage recurrence was found in 130 patients, of which 67 people relapsed. Low risk was defined in 223 cases, of which, actually, there was no recurrent bleeding in 200 cases. The sensitivity of the method was $74 \%$ (67of 90 ), and specificity was $76 \%$ (200 of 263). The accuracy of the method was $76 \%$ (267 of 353 ), and the predictive value of a positive result was $52 \%$ (67 of 130). That is, in the training sample, the method showed a greater informative value than the classifications of G.P. Giderim or J.A. Forrest. The measure of the gamma relationship for allocating patients to groups by the original method was $-0.79(p<0.001)$.

Assessing informative value of the developed method for predicting recurrent bleeding from nine traits

At the second stage of our project, the informativeness of the developed method was assessed on an independent sample of 126 patients with GDUB, who were treated at the emergency surgical department of the State Healthcare Institution Academician V.N. Koshelev Saratov City Clinical Hospital No. 6 from 2001 to 2009. Relapse of bleeding occurred in 63 patients.

Patient data were uploaded to the System. With the help of the analytical module of the System, the informativeness of a novel technique for predicting recurrent bleeding was evaluated by nine predictive features, or signs. The risk was assessed in 119 patients with a full set of clinical, laboratory and endoscopic signs. The informativeness of this method in the test sample was slightly worse than in the training sample. A high risk of recurrence was found in 61 patients, which was confirmed in 42 cases (predictive value of $68.9 \%$ ). Low risk was identified in 58 patients, the prognosis was justified in 42 cases. The sensitivity of the method was $72.4 \%$ ( 42 of 58 ), the specificity was $68.9 \%$ ( 42 of 61 ). The accuracy of the method was $70.6 \%$ (84 out of 119).

Table 6 presents the informativeness indicators of the original method for predicting recurrent bleeding in comparison with the classifications by J.A. Forrest and G.P. Giderim. Indicators of informativeness of other methods for this group of patients were presented in our earlier publications [10].

Despite the fact that both the first and second samples for classifications by J.A. Forrest and G.P. Giderim were test samples, the informativeness indicators of the methods differed significantly. This was due to the difference between groups 1 and 2 in the distribution of individual traits. The significance of clinical, laboratory and endoscopic characteristics used for dividing patients by the risk severity of recurrent bleeding was assessed using the gamma relationship measure (Table 7).

As can be seen from the data presented in Table 7, the relationship between hemodynamic parameters and patients belonging to groups with or without recurrent bleeding was significantly stronger in the test sample. This also applied to the volume of blood loss. However, the ulcer size in the test sample influenced the severity of risk of recurrent hemorrhage significantly less. For ulcer localization and presence of concomitant pathology, there were no significant relationships among the patient allocation to the group with or without recurrence of bleeding. Hence, it can be concluded that the test sample had differences that affected the information content of the methods in terms of predictability of the hemorrhage recurrence.

Nonetheless, the developed multivariate method showed similar information content both in the training sample and test sample, which indicated a more reliable risk assessment result in comparison with the simplest procedures.

\section{Discussion}

The use of methods for predicting the course of the disease and assessing the severity of the condition significantly improves the treatment results in patients with GDUB $[6,12]$. However, in practice, they are used much less frequently than one could have expected. For example, in the UK, rating scales are used in only $19 \%$ of hospitals [13]. The reason for this pattern may be established traditions, and lack of interest in employees and administration [14]. Another important motive is the complexity of the calculations and the need to perform additional actions, even when using computer programs. 
Table 7. Measurements of gamma relationship between main features and patient allocation to groups for two studies

\begin{tabular}{|c|c|c|}
\hline \multirow{2}{*}{ Signs for assessing the recurrence risk of gastroduodenal ulcer bleeding } & \multicolumn{2}{|c|}{ Gamma } \\
\hline & Group $1 \mathrm{~N}=409$ & Group $2 \mathrm{~N}=126$ \\
\hline Signs of unstable hemodynamics: pulse $\geq 100$ per min. on admission and / or having a collapse before admission & -0.574 & -0.777 \\
\hline Signs of hemorrhagic shock: systolic blood pressure $<100 \mathrm{mmHg}$ at hospitalization & -0.537 & -0.859 \\
\hline The presence of severe blood loss sensu A.I. Gorbashko & -0.293 & -0.531 \\
\hline Vomiting of unchanged or reduced blood & -0.406 & -0.397 \\
\hline Presence of any clinically significant pathology & -0.470 & $-0.127^{*}$ \\
\hline High risk features sensu classification by J.A. Forrest & 0.487 & 0.423 \\
\hline Ulcer localization: the body and cardiac section of the stomach, ulcers of the posterior wall of the duodenum & -0.434 & $-0.221 *$ \\
\hline Ulcer size vs. its localization: gastric ulcer $\geq 1.6 \mathrm{~cm}$; duodenal ulcer $\geq 1 \mathrm{~cm}$ & -0.655 & -0.408 \\
\hline Presence of a deep ulcer & -0.619 & -0.600 \\
\hline
\end{tabular}

* - the relationship is not statistically significant $(p<0.05)$.

Another reason for low commitment to risk assessment arises from the results of comparative analysis of different assessment systems. For example, when comparing T.A. Rockall and O. Blatchford with J.A. Forrest, we discovered the advantage of the latter classification in predicting the recurrence of bleeding [15, 16]. That is, the assessment of ulcer surface condition was quite adequate for making tactical decisions. In addition, the distinctive clinical picture of bleeding and the result of gastric lavage made it possible to set indications for hospitalization, intensive care, and endoscopic examination [4, 5]. Evaluation of hemodynamics significantly complements the endoscopic picture in predicting recurrence of GDUB [17]. These data are comparable with the results of our present and previous studies [10].

In their review article, S. Monteiro et al. (2016), conclude that it is necessary to use predictive methods and risk assessment in the context of existing recommendations in accordance with physician's experience and intuition [6]. The doctor's intuition and experience were emphasized by N.L. de Groot et al. as well [7]. The authors compared the effectiveness of assessing various risks, including recurrent bleeding and death, using the grading scales by O. Blatchford and T.A. Rockall, with the effectiveness of intuitive risk assessment by experienced gastroenterologists in 974 patients. The effectiveness of these scales was higher than the intuitive risk assessment. However, the best results were obtained with the combined use of scales and physician's experience.

Some studies have emphasized the need to separate features, depending on the objective of the forecast. For example, for predicting recurrent hemorrhage, the severity of bleeding and ulcer characteristics were of greatest importance, while for assessing the risk of death, these factors included the age, physical condition of the patient, and the presence of concomitant diseases $[18,19]$. In our study, we set the task of identifying significant signs (features) for predicting solely recurrent bleeding.

Taking into account the signs, by which a significant difference was established between the main group and the comparison group, it was possible to give a general characteristic of patients with a high risk of bleeding recurrence. All described changes suggested the presence of certain morphofunctional, primarily destructive, changes in the ulcer area, causing the recurrent nature of bleeding, in some patients. From this standpoint, individual signs, indicating a high risk of recurrent bleeding could be considered manifestations of a pre-relapse syndrome [20]. Previously, we used the term 'unstable hemostasis' to denote a state of high risk of recurrent bleeding [21].

In this study, it was possible to trace the effect of the representativeness of the sample, used for comparative analysis, on the information content of individual methods. First of all, this refers to the simplest methods using a limited number of features. When analyzing methods, it is necessary to take into account the stability (i.e., narrow variation range) of the forecasted results for different clinical material, which is only possible for multifactorial methods.

For example, for G.P. Giderim's classification in the first study with a sample of 409 patients, the predicted outcomes were much less reliable than in the second study with fewer patients. This indicates the instability of the forecast for a limited number of features and the high dependence of the information content of the method on the representativeness of the sample.

At the same time, J.A. Forrest's classification, based on just a single feature, actually allowed predicting recurrence of bleeding. Despite its limited accuracy, this method is widely adopted which is quite justifiable.

However, the condition of the ulcer surface changes rapidly over time, in contrast to the size, depth and localization of the ulcer. The latter predictive features are associated with the degree of destructive morphological and functional changes in the ulcer to a greater extent. A deep ulcer is more likely to lead to arrosion of large blood vessels, bleeding from which has more vivid clinical manifestations and a dangerous recurrent nature. In our opinion, these changes can be considered a morphological substrate of the pre-relapse syndrome.

Our original predictive method showed equally good results for both samples, which makes it possible to recommend it for predicting recurrence of gastroduodenal ulcer bleeding. However, it must be understood that the assessment of the risk of recurrent bleeding is just one of the factors that determine the treatment tactics. With a high risk of hemorrhage recurrence, there is a reason for a repeated endoscopic examination with performing, if necessary, an endoscopic intervention. In some cases, a high risk may serve as an additional condition for justifying urgent surgical intervention. Other aspects of treatment tactics (indications for blood transfusion or hospitalization at the intensive care unit, as well as the choice of the operation option) are determined by other criteria: the volume of blood loss, the severity of somatic pathology, the degree of surgical and anesthetic risk, etc. All of the above explain why Russian medicine does not use some kind of universal risk assessment scale.

\section{Conclusion}

The threat of recurrent bleeding should be judged by the combination of clinical and endoscopic signs: unstable hemodynamics, severity of blood loss, the nature of vomiting, the presence of concomitant pathology, the state of the ulcer surface sensu J.A. Forrest; and the ulcer size, location and depth. 
Prediction of recurrent bleeding from one or two signs is inferior in informational content, albeit slightly, to the multifactorial method. In addition, the assessment of the entire set of symptoms allows to more fully substantiate the treatment tactics for ulcer bleeding. The developed method for predicting the recurrence of ulcer bleeding from nine features, or signs, has an optimal ratio of sensitivity and specificity, which ensures a prediction accuracy of over $70 \%$ and a positive predictive value of $68.9 \%$.

\section{Funding}

The experimental study was carried out as part of the scheduled scientific research plan of Saratov State Medical University. There was no external financial support.

\section{Conflict of interest}

We have no conflict of interest to declare.

\section{Ethical approval}

The study was approved by the Ethics Committee at Saratov State Medical University, Saratov, Russia.

\section{References}

1. Barkun AN, Bardou M, Kuipers EJ, Sung J, Hunt RH, Martel M, et al; International Consensus Upper Gastrointestinal Bleeding Conference Group. International consensus recommendations on the management of patients with nonvariceal upper gastrointestinal bleeding. Ann Intern Med 2010; 152(2): 101-113. https://doi.org/10.7326/0003-4819-152-2-201001190-00009.

2. Barkun AN, Almadi M, Kuipers EJ, Laine L, Sung J, Tse F, et al. Management of Nonvariceal Upper Gastrointestinal Bleeding: Guideline Recommendations From the International Consensus Group. Ann Intern Med 2019; 171(11): 805-822. https://doi.org/10.7326/m191795.

3. 3. Gastroduodenal Ulcer Bleeding. Clinical Guidelines. Adopted at the Russian National Consensus Conference on the adoption of national clinical guidelines on June 6, 2014, Voronezh. Moscow - Voronezh. 2014; 9 p. Russian. https://www.mrckb.ru/files/yazvennye gastroduodenalnye_krovotech eniya.PDF

4. Iwasaki H, Shimura T, Yamada T, Aoki M, Nomura S, Kusakabe A, et al. Novel nasogastric tube-related criteria for urgent endoscopy in nonvariceal upper gastrointestinal bleeding. Dig Dis Sci 2013; 58(9): 2564-2571. https://doi.org/10.1007/s10620-013-2706-x.

5. McCarthy DM. Gastrointestinal bleeding: who needs urgent endoscopic intervention? Dig Dis Sci 2013; 58(9): 2452-2454. https://doi.org/10.1007/s10620-013-2757-z.

6. Monteiro S, Gonçalves TC, Magalhães J, Cotter J. Upper gastrointestinal bleeding risk scores: Who, when and why? World $J$ Gastrointest Pathophysiol 2016; 7(1): 86-96. https://doi.org/10.4291/wjgp.v7.i1.86.

7. de Groot $N$, van Oijen $M$, Kessels $K$, Hemmink M, Weusten B, Timmer $\mathrm{R}$, et al. Prediction scores or gastroenterologists' Gut Feeling for triaging patients that present with acute upper gastrointestinal bleeding. United European Gastroenterol J 2014; 2(3): 197-205. https://doi.org/10.1177/2050640614531574.

8. Forrest JA, Finlayson ND, Shearman DJ. Endoscopy in gastrointestinal $\begin{array}{llll}\text { bleeding. } \quad \text { Lancet } 2(7877): & \text { 3974; }\end{array}$ https://doi.org/10.1016/s0140-6736(74)91770-x.

9. Giderim GP, Chikala ET, Gutsu VM, Kontsu GI. Tactics for gastrointestinal bleeding in an air ambulance. Pirogov Russian Journal of Surgery 1992; 68(9-10): 24-29. Russian.
10. Potakhin SN, Shapkin YuG. Comparative analysis of methods for predicting of peptic ulcers rebleeding. Novosti Khirurgii 2020; 28(2): 141-149. Russian. https://doi.org/10.18484/2305-0047.2020.2.141.

11. Gorbashko Al. Ways to improve the results of acute gastrointestinal bleeding treatment. Grekov's Bulletin of Surgery 1989; (6): 16-21. Russian.

12. Jairath $\mathrm{V}$, Barkun AN. The overall approach to the management of upper gastrointestinal bleeding. Gastrointest Endosc Clin N Am 2011 21(4): 657-670. https://doi.org/10.1016/j.giec.2011.07.001.

13. Barkun AN HI, Armstrong D, Dawes M, Donner A, Stitt LW, Enns RA, et al. Improving adherence to guidelines when managing non-variceal upper gastrointestinal bleeding: A national cluster randomized trial of a multifaceted strategy. Gastroenterology. 2010; 138(Suppl 1): S-327. https://doi.org/10.1016/S0016-5085(10)615053.

14. Barkun AN, Bhat $M$, Armstrong D, Dawes $M$, Donner A, Enns R, et al. Effectiveness of disseminating consensus management recommendations for ulcer bleeding: a cluster randomized trial. CMA 2013; 185(3): E156-E166. https://doi.org/10.1503/cmaj.120095.

15. Heldwein W, Schreiner J, Pedrazzoli J, Lehnert P. Is the Forrest classification a useful tool for planning endoscopic therapy of bleeding peptic ulcers? Endoscopy 1989; 21(6): 258-262. https://doi.org/10.1055/s-2007-1010729

16. Kim BJ, Park MK, Kim SJ, Kim ER, Min BH, Son HJ, et al. Comparison of scoring systems for the prediction of outcomes in patients with nonvariceal upper gastrointestinal bleeding: a prospective study. Dig Dis Sci 2009; 54(11): 2523-2529. https://doi.org/10.1007/s10620-0080654-7.

17. Bornman PC, Theodorou NA, Shuttleworth RD, Essel HP, Marks IN. Importance of hypovolaemic shock and endoscopic signs in predicting recurrent haemorrhage from peptic ulceration: a prospective evaluation. Br Med J (Clin Res Ed) 1985; 291(6490): 245-247. https://doi.org/10.1136/bmj.291.6490.245.

18. Chiu PW, Ng EK. Predicting poor outcome from acute upper gastrointestinal hemorrhage. Gastroenterol Clin North Am 2009; 38(2): 215-230. https://doi.org/10.1016/j.gtc.2009.03.009.

19. Nahon $S$, Hagège $H$, Latrive JP, Rosa I, Nalet B, Bour B, et al; Groupe des Hémorragies Digestives Hautes de I'ANGH. Epidemiological and prognostic factors involved in upper gastrointestinal bleeding: results of a French prospective multicenter study. Endoscopy 2012; 44(11) 998-1008. https://doi.org/10.1055/s-0032-1310006.

20. Shapkin YuG, Potakhin SN, Belikov AV, Uryadov SE, Ivanov RYu. Diagnostics of the pre-recurrent syndrome in bleeding ulcers of the stomach and duodenum. Grekov's Bulletin of Surgery 2004; 163(1): 43 46. Russian. https://www.elibrary.ru/item.asp?id=30269007.

21. Shapkin YuG, Klimashevich VYu, Potakhin SN, Matveeva EN Possibilities of improving surgical tactics for bleeding gastroduodenal ulcer. Grekov's Bulletin of Surgery 2000; 159(2): 24-26. Russian.

\section{Authors:}

Sergey N. Potakhin - MD, PhD, Associate Professor, General Surgery Department, Saratov State Medical University, Saratov, Russia. http://orcid.org/0000-0002-4159-3047.

Yuri G. Shapkin - MD, DSc, Professor, Head of the General Surgery Department, Saratov State Medical University, Saratov, Russia. http://orcid.org/0000-0003-0186-1892. 